\title{
Goggle-like Appearance of Injured Cerebellothalamic Axons Surrounding Red Nuclei in Holmes Tremor
}

\author{
Gencer Genc, Stephen Jones, Hubert H. Fernandez, Scott E. Cooper
}

Keywords: Holmes tremor, Red nucleus, Magnetic resonance imaging, Cerebellothalamic axons

A 66-year-old man on rivaroxaban (Xarelto) for atrial fibrillation experienced a pontine hemorrhage. He survived the acute hospitalization and was discharged to a rehabilitation facility in a quadriparetic state. Over the 4 months following the hemorrhage, he developed a tremor, first in the lower and then in the upper extremities, which prompted his referral to the Movement Disorders clinic.

On examination of visual tracking, there was no horizontal movement of the left eye and no adduction of the right eye. He had distal more than proximal, left more than right, and lower more than upper limb weakness, ranging from $3 / 5$ in the left leg to $4 / 5$ in the right arm, with depressed deep tendon reflexes. In the left upper extremity, he had a tremor that was present at rest, with posture, and with action. The movements met the description of Holmes tremor in the Consensus Statement of the Movement Disorder Society on Tremor. ${ }^{1}$ The movements lacked the jerky quality of myoclonus, the randomness of chorea, or the sustained twisting quality of dystonia, nor was there any pulling toward a null position as in dystonic tremor. There was also head tremor with activation of the left shoulder girdle and neck muscles. When he held the left arm outstretched, supporting it against gravity, and the examiner shoved the limb out of position, the limb oscillated for several cycles before settling into position again. Pointing (finger-chin-finger) was ataxic, and there were mild athetoid movements of the fingers. A similar resting tremor was present in the left lower extremity, although weakness there precluded testing postural or kinetic tremor. A postural and kinetic tremor similar to that of the left upper extremity was seen in the right upper extremity as well, but not as severe. There was no bradykinesia or rigidity. We recommended a trial of levodopa, ${ }^{2-6}$ and, if this failed, leviteracitam, ${ }^{7,8}$ but the patient died before results of this could be determined.

Magnetic resonance imaging of the brain done at 1 day after the acute hemorrhage shows the pontine hemorrhage (Figure 1A). Higher cuts, at the level of the midbrain, show a striking "gogglelike" appearance of T2 hyperintensity representing anterograde axonal edema extended rostrally to midbrain (Figure 1B) where it is seen in cerebellothalamic fibers surround the red nuclei.

It is well-known that mesencephalic lesions may cause a lowfrequency tremor present at rest, with posture, and with action (Holmes tremor). The term "rubral" for such tremors implies a role for the red nucleus (RN), but the critical structure may instead be cerebellar efferents, ${ }^{9}$ some of which synapse in the parvocellular $\mathrm{RN}$, whereas others wrap around the $\mathrm{RN}$ en route to thalamus. ${ }^{10}$ The question is difficult to resolve because it would be rare for a mesencephalic lesion to affect a substantial portion of the cerebellothalamic fibers while sparing the RN.

Our patient's Holmes tremor was caused by a pontine lesion some distance away from the midbrain and is thus a "cerebellar outflow tremor." Its remarkable feature is the magnetic resonance imaging, which shows a midbrain lesion, presumably representing edema associated with anterograde degeneration of axons damaged in the pons. To our knowledge, this is the first case in which a midbrain lesion limited to cerebellar efferents, while sparing surrounding structures, has been imaged in a case of Holmes tremor.

\section{ACKNOWLEDGMents AND Funding}

No funding was received for this report.

\section{Disclosures}

HHF has received honoraria from Advanced Health Media, Cleveland Clinic CME, Medical Communications Media, Movement Disorders Society, Vindico Medical Education, Ipsen, Merz Pharmaceuticals, Pfizer, Teva Neuroscience, and Zambon Pharmaceuticals, as a speaker in CME events and/or consultant; has received personal compensation for serving as co-Medical Editor of the Movement Disorders Society Website; has received royalty payments from Demos Publishing and Manson LTD for serving as a book author/editor; has received research support from Abbott, Acadia, Biotie Therapeutics, EMD-Serono, Huntington Study Group, Merck, Michael J. Fox Foundation, Movement Disorders Society, National Parkinson Foundation, National Institutes of Health/National Institute of Neurological Disorders and Stroke, Novartis, Parkinson Study Group, Synosia, and Teva,

From the Neurological Institute, Center for Neurological Restoration, Cleveland Clinic, Cleveland, Ohio (GG, HHF); Gumussuyu Military Hospital, Department of Neurology, Istanbul, Turkey (GG); Imaging Institute, Division of Neuroradiology, Cleveland Clinic, Cleveland, Ohio (SJ); Department of Neurology, University of Minnesota, Minneapolis, Minnesota (SEC).

Received October 14, 2015. Final Revisions Submitted August 6, 2016. Date of ACCEPTANCE OCTOBER 16, 2016.

Correspondence to: Gencer Genc, Gumussuyu Military Hospital, Department of Neurology, Taksim, Beyoglu, 34437, Istanbul, Turkey. Email: gencerg@ gmail.com 
(A)

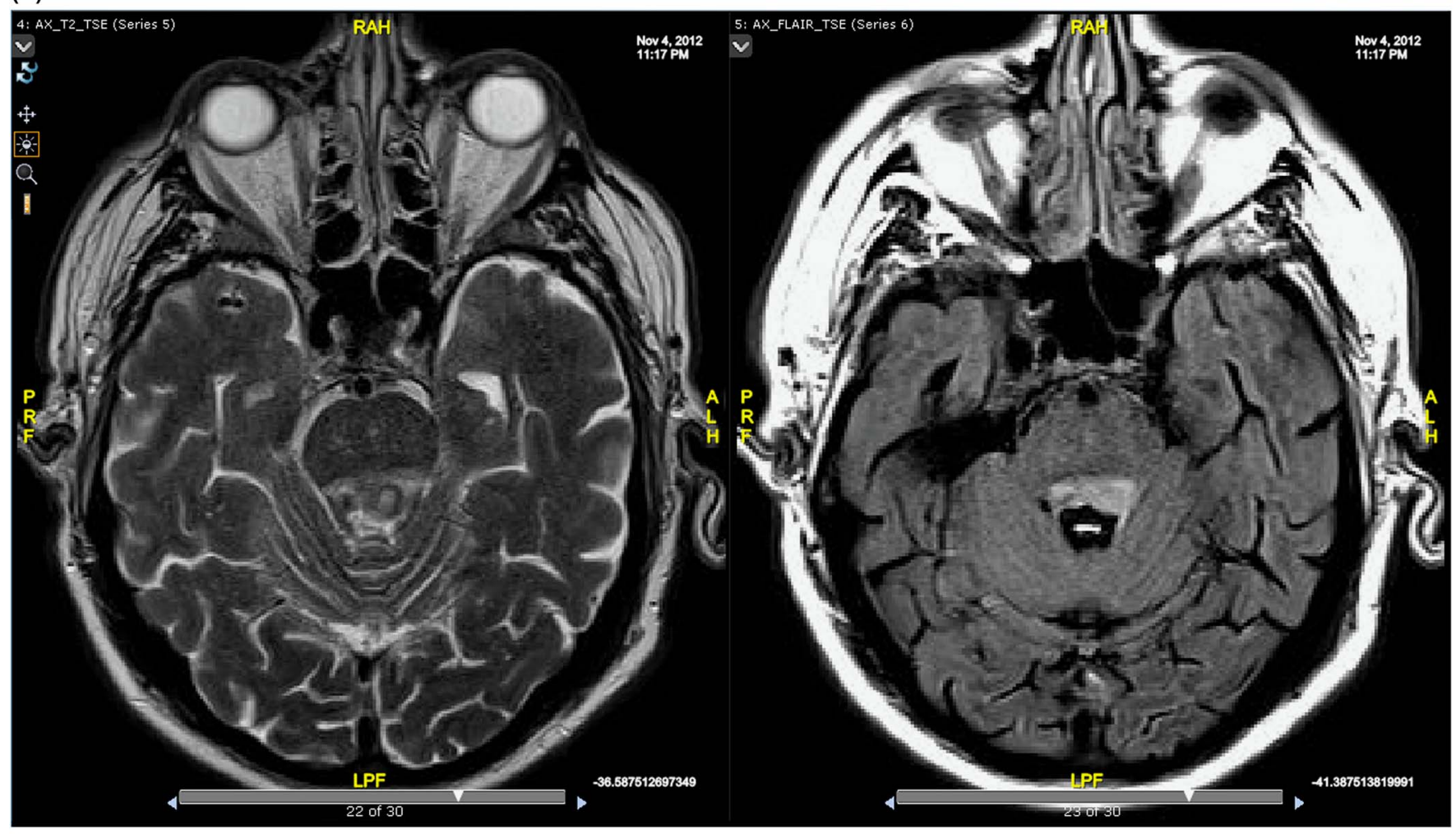

(B)

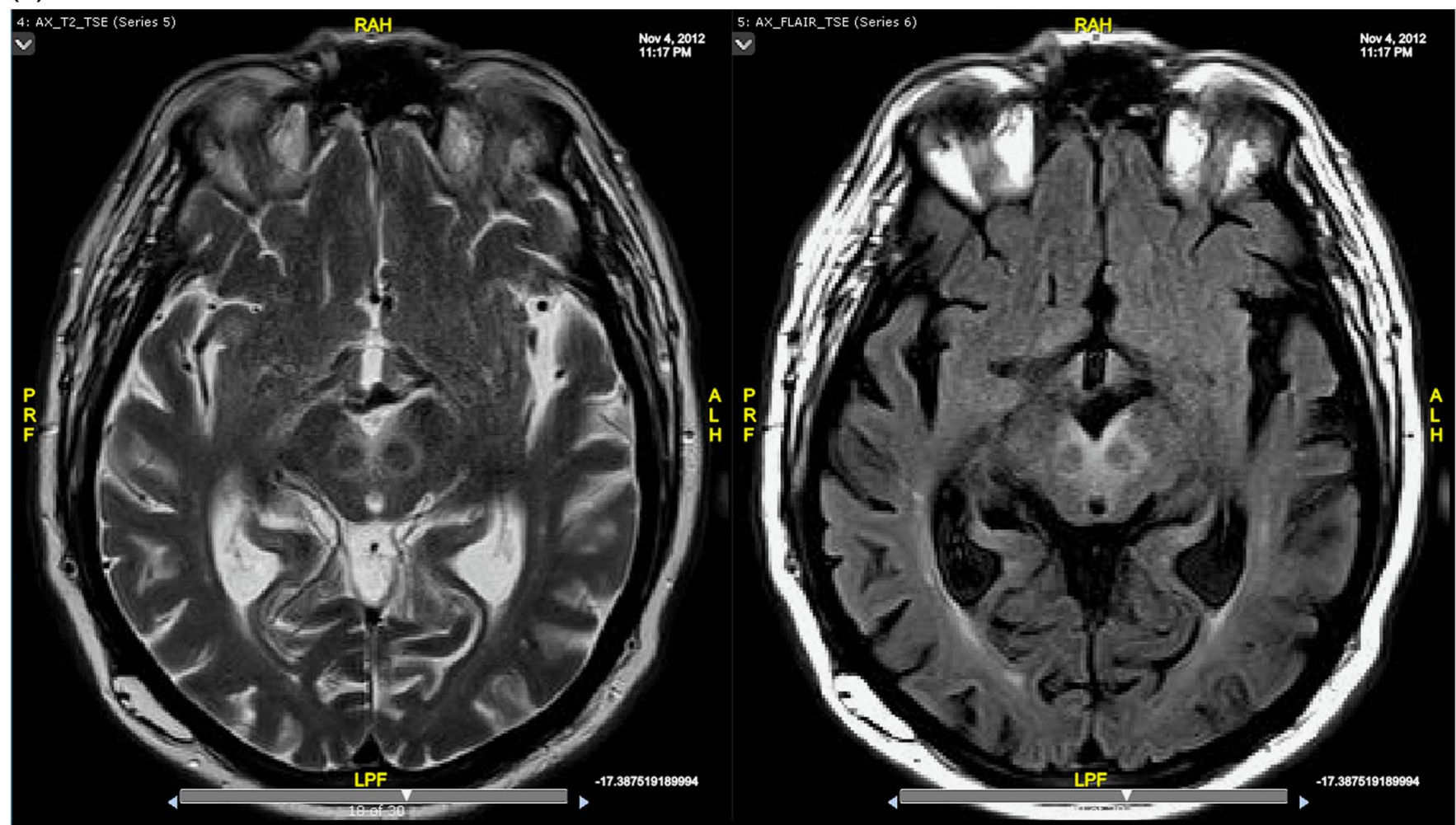

Figure 1: (A) Pontine hemorrhage. (B) Goggle-like appearance in midbrain representing anterograde axonal edema in which cerebellothalamic fibers surround red nuclei. 
but has no owner interest in any pharmaceutical company. GG, $\mathrm{SJ}$, and SEC report no disclosures.

\section{REFERENCES}

1. Deuschl G, Bain MA, Brin M, and members of the Ad Hoc Scientific Committee. Consensus statement of the Movement Disorder Society on Tremor. Mov Disord. 1998;13:2-23.

2. Findley LJ, Gresty MA. Suppression of "rubral" tremor with levodopa. Br Med J. 1980;281:1043.

3. Raina GB, Velez M, Pardal MF, Micheli F. Holmes tremor secondary to brainstem hemorrhage responsive to levodopa: report of 2 cases. Clin Neuropharmacol. 2007;30:95-100.

4. Boelmans K, Gerloff C, Munchau A. Long-lasting effect of levodopa on Holmes' tremor. Mov Disord. 2012 Aug;27(9): 1097-8.
5. Vélez M, Cosentino C, Torres L. Levodopa-responsive rubral (Holmes') tremor. Mov Disord. 2002;17:741-2.

6. Woo JH, Hong BY, Kim JS, et al. Holmes tremor after brainstem hemorrhage, treated with levodopa. Ann Rehabil Med. 2013; 37:591-4.

7. Ferlazzo E, Morgante F, Rizzo V, et al. Successful treatment of Holmes tremor by levetiracetam. Mov Disord. 2008;23:2101-3.

8. Striano P, Elefante A, Coppola A, Tortora F, Zara F, Minetti C. Dramatic response to levetiracetam in post-ischaemic Holmes' tremor. BMJ Case Rep. 2009; published online January 23, 2009.

9. Zeuner KE, Deuschl G. An update on tremors. Curr Opin Neurol. 2012;25:475-82.

10. Mori S, Wakana S, Nagae-Poetscher LM, van Zijl PC. MRI atlas of human white matter. Amsterdam, The Netherlands: Elsevier; 2005. 